\title{
The Unaltered Body? Rethinking the Body When IVF Fails
}

\author{
Karen Throsby
}

\begin{abstract}
Drawing on a series of interviews with women and couples who have had IVF unsuccessfully and who have stopped treatment, this paper challenges the assumption that the (re)production of novel entities that is associated with the new reproductive and genetic technologies only occurs when treatment succeeds. I argue that the work of accounting for the experience of IVF failure generates, at least potentially, a novel, post-IVF body whose construction fragments the category of childlessness, and redefines what constitutes the (in)fertile body. These reconfigurations of normative categories of reproductive belonging serve to normalise their situation and resist the blame and exclusion that often accompanies the experience of infertility. The paper concludes that the assumption that innovation only occurs when treatment succeeds reproduces the problematic definition of IVF by its successes.
\end{abstract}

Keywords: IVF failure, body, innovation

\section{Introduction}

As a conceptive, reproductive technology, it is clear that in vitro fertilisation (IVF) has the production of new bodies as its literal goal, as represented by the iconic figure of the IVF baby. However, IVF is also associated with the production of a constellation of novel entities beyond, but intimately connected to, the IVF baby. Conceptualising IVF as a disciplinary technique, Jana Sawicki argues that IVF produces "new objects and subjects of knowledge, by inciting and channelling desires, generating and focusing individual and group energies, and establishing bodily norms and techniques for observing, monitoring and controlling bodily movement, processes and capacities" (Sawicki, 1991: 83). These new objects and subjects of knowledge are the focus of intense public, scientific and policy debate (see, for example, Franklin, 1993; Parry, 2003), with diverse interests, desires and energies jostling to stabilise their uncertain and unfamiliar status, meanings and possibilities. Novel entities, then, such as the pre-embryo, cryopreserved embryos, or human embryonic stem cells are as much the products 
of IVF as are its "miracle" babies.

While these more obviously novel entities have received a considerable amount of scrutiny and interest, very little attention has been paid to the ways in which the engagement with IVF changes the social and cultural meanings of the embodied lives of those undergoing treatment. ${ }^{1}$ This is an exclusion that is particularly marked in the context of unsuccessful IVF. In the first instance, this absence can be understood as reflecting the more general paucity of narratives of treatment failure within popular, academic, clinical and policy discourse, but it also reflects the cyclical logic of IVF, which appears to return those undergoing treatment unsuccessfully back to where they started from; back to the suspended state of being "not yet pregnant" (Greil, 1991). However, the reality of IVF is that almost $80 \%^{2}$ of all treatment cycles end in failure, meaning that many have to detach themselves from the cyclicality of the treatment process without the desired resolution of pregnancy.

Charis Thompson (2005) argues that the assisted reproductive technologies (ARTs) can be understood in terms of "ontological choreography" - "the dynamic coordination of the technical, scientific, kinship, gender, emotional, legal, political, and financial aspects of ART clinics" (2005: 8). This ontological choreography constitutes a "deftly balanced coming together of things that are generally considered parts of different ontological orders (part of nature, part of the self, part of society)" (2005: 8). When treatment succeeds, Thompson argues, "ontological choreography leads to new kinds of reproduction and new ways of making parents" (2005: 9) - a process which she describes as one of "ontological innovation" (2005: 9). Conversely, for Thompson, the failure of treatment to facilitate pregnancy is marked by an absence of ontological innovation, constituting instead a moment of failed choreography in the complex "coming together" of assisted reproduction (2005: 9). This perception of treatment failure is reproduced by Robert Winston - one of the UK's most high profile spokesmen for IVF - in his "definitive guide" to the ARTs:

If the treatment works, pregnancy is immediate; if it fails, the person treated is not only not pregnant, but physically unchanged, and the medical condition which gave rise to the reproductive problem is unaltered. (Winston, 1999: vii; emphasis added)

In this paper, I want to argue that this reading of treatment failure overlooks the ways in which the unsuccessful engagement with IVF also generates novel, technologically-mediated forms of embodiment, and that the body is never left unchanged by its engagement with IVF. ${ }^{3}$ These new forms of embodiment, I want to argue, are just as important for feminist technoscientific writing as the more spectacular entities of treatment success; indeed, it could be argued that the ease with which they can be overlooked is precisely what makes them of such interest. This paper argues that IVF failure, and the end of treatment without a baby, generate the possibilities for a post-IVF body that is fundamentally distinct from the "not yet pregnant" body of the present or future IVF patient. This paper explores what it means for women to be post-IVF without a child (or the desired number of children); what kinds 
of material-discursive ${ }^{4}$ governance constitute the post-IVF body; and what possibilities the post-IVF body presents for thinking about technologies, bodies and the social contexts within which the ARTs are made meaningful.

The paper will begin with a brief methodological discussion in order to provide the context for the interview data from which the main analysis presented in the paper is drawn. This will be followed by a discussion of the ways in which IVF failure is commonly conceptualised, and I suggest that the management and negotiation of the experience of IVF failure can be understood as exemplifying "outside belonging" (Probyn, 1996), opening up new possibilities for the disruption and reconfiguration of the reproductive categories. The main analysis section of the paper will look at two key aspects to the construction of the post-IVF body which can be seen as central to the production of the post-IVF body: firstly, the fragmentation of the category of childlessness; and secondly, the reclamation of the post-IVF body as fertile. The paper will conclude with a brief discussion.

\section{Methodology}

This paper draws on a data from my $\mathrm{PhD}$ research project - an interview-based study, completed in 2002, of people's experiences of IVF failure and the end of treatment. Initially, the research asked what the key factors were that informed the decision to stop treatment; how the experience of IVF failure impacted upon perceptions of the technology; and how the experience of treatment failure impacted upon the experience of infertility. However, in reality, the task of iden- tifying "factors" in the decision to end treatment proved far less fruitful than the accounts that the participants gave about learning to live with the challenges and possibilities that IVF failure presented to them. It is this work of making sense of treatment failure, rather than the moment of stopping itself, that subsequently became the focus of the research.

The participants for the research were recruited through the dormant patient records of a specialised unit within a large National Health Service (NHS) teaching hospital. The hospital ethics committee approved access to the records in September 1999, subject to the conditions of the clinic's HFEA (Human Fertilisation and Embryology Authority) license, to which my name was also added. Through the dormant patient records, I identified former patients whose most recent cycle had been unsuccessful and had taken place between 1992 and 1997; people who met these criteria but who had suffered particular traumas such as late miscarriage, relationship breakdown mid-treatment or the death of a partner were not included. This list was then reviewed by two longstanding members of the clinic team in order to check that nobody had been included who they knew had had a particularly difficult experience that might not necessarily have been noted on the medical record. In total, 350 letters were sent out on hospital-headed paper, signed by both the clinic director and myself, inviting them to participate in two interviews, approximately 6 months apart, as well as to complete questionnaires covering demographic information and treatment histories. The final list of participants recruited in response 
to this letter included 15 women and 13 couples. ${ }^{5}$ They were all in committed heterosexual relationships at the time of the interviews, with the exceptions of one woman who was separated from her husband and in the process of seeking a divorce, and another who separated from her partner during the study.

The participants were predominantly, but not exclusively, white, middle class and educated to degree or professional level. The relative uniformity of the participants in terms of class and race is a well-established problem in research in this field (see also Sandelowski, 1993; Daniluk, 1996; Franklin, 1997), and as the technology becomes increasingly mainstream and its patient population becomes increasingly diverse, it is important to be aware of these limitations. However, in spite of this relatively common ground, the participants' experiences of treatment, and the extent to which they had engaged with it, varied enormously. The number of cycles of treatment they had undergone ranged from a single cycle up to 13 , and the expenditure on treatment ranged from very little up to well over $£ 20,000$, with most of the participants having undergone treatment at more than one clinic, often combining self-funded cycles in NHS or private facilities with treatment funded by health authorities (where they were available).

The interviews usually took place in their homes, with couples always interviewed together, and the interviews were taped, transcribed orthographically and analysed using discourse analysis (Potter and Wetherell, 1987; Gill, 1996; Gill, 2000; Wood and Kroger, 2000). In response to concerns that the process of being interviewed might raise difficult issues for the participants, at their first interview they were given the contact details of the clinic's independent counsellor, who was aware of the project. ${ }^{6}$ Pseudonyms have been used throughout this paper, and all identifying information has been changed, in order to protect the anonymity of the participants in the writing up of the research.

\section{Representations of IVF Failure}

As a reproductive technology, IVF is conventionally defined by its successes - the IVF babies. However, this is not to say that IVF failure is completely absent from those dominant representations. For example, it appears in what could be described as "persistence" stories, where repeated failures are endured until the determined couple are rewarded with their "miracle baby". Failure also appears in the form of salutary tales of "desperate excess", where the inability to place limits around the engagement with treatment is constructed as ruinous to relationships, and emotional and financial well-being. Ironically, both of these representations of failure are predicated on discourses of treatment success: the former offering success through persistence, constructing the end of treatment without a baby as a lack of commitment or staying power; and the latter constructing life without biological children as inevitably catastrophic, and therefore treatment success, or stoic suffering, as the only acceptable outcomes.

The intolerability of non-reproduction is borne out by RobertWinston, who describes life without children as a tragedy "unequalled in any sphere of life" (1999: vii), continuing that childless people are "barred from contributing to the 
continuity of human existence" (1999: vii).The point is driven home with the assertion that "having a child brings parents a kind of immortality which childless couples may only watch with envy" (1999: vii). There is little space within this discourse for the narratives of those for whom IVF has failed, even though this remains the dominant experience of the technology. The experiences of those for whom treatment fails and who subsequently stop treatment are particularly easy to overlook from the clinic perspective, since those individuals are no longer within the clinical domain as patients and are therefore literally out of view. This is exemplified in Charis Thompson's study, when during a day observing at the clinic, a physician hurried in to tell her that if she ran, she would be able to catch up with a patient who had just left who had "decided to stop treatment even though she was not pregnant" (2005: 94). The physician assured her that she was unlikely to see a similar case during her fieldwork, and Thompson goes on to confirm that this was indeed the case, outside of those who were forced to stop on medical advice or who could no longer afford treatment. However, while Thompson reads this as evidence of the "culture of perseverance" (2005: 94) in the clinic, my research has also shown that the decision to end treatment was rarely made and announced in the clinic, but rather, arrived at over a period of time away from it, making the ending of treatment less obvious to the clinicians.

Another site where treatment failure is usually, if marginally, included is the proliferating genre of official and popular advice texts for those experiencing infertility. The issue of treatment failure conventionally occurs towards the end of these texts, either embedded as one of a number of possible outcomes (e.g. Brian, 1998) or as a final chapter (e.g. McGrail, 1999). These concluding chapters characteristically end on a sympathetic, but upbeat note, highlighting the ways in which IVF failure can reaffirm relationships and provide resolution through having tried everything possible. In a brief final page devoted to the issue of when to "give up" treatment, RobertWinston illustrates the contradictory norms which govern these upbeat conclusions:

Normal people, though they feel desperate at the time, come out of this feeling much better and stronger. Once you have given up fertility treatment, your whole life can be resolved and you can get on with the other valuable things within it. [...] This may sound strange, but so many couples find that it has strengthened their relationship and that it has enabled them to deal with other problems in a much more sensible and focused way. Infertile people, if they are not careful, can allow their treatment to destroy their well-being and to destroy the things and relationships they most value. It is unwise to let this happen to you. It is worth recognising that you have gone through definitive treatment and may now need to close the door. (Winston, 1999: 222-3)

Feeling "better and stronger" is a familiar trope in narratives of adversity, and is set out here as the normative outcome; indeed, no less than the resolution of "your whole life" can be achieved by a well-handled exit from treatment by "normal" people, according to Winston - a finding which is at odds with the unremittingly negative portrayal of childlessness in the book's preface. But the responsibility for achieving this state of 
well-being falls directly to the patients themselves (and particularly to the female partners to whom the book is primarily addressed) - it is they who otherwise risk allowing the destruction of lives and relationships.

These normative constructions of failure are repeated in the HFEA Guide to Infertility and Directory of Clinics (HFEA, 2005). This publication includes a twopage section entitled "When Treatment Fails" (HFEA 2005: 50-51), positioned as the final section of a chapter which reviews all the treatment options, and which is immediately preceded by a section headed "Pregnant at Last!" This latter is illustrated, slightly surreally, with a large picture of what appears to be a family group of dolphins - two adults and an infant. The section on treatment failure, on the other hand, is illustrated more ominously with a picture of an eggtimer, with the sand draining away from its upper portion. ${ }^{8} \mathrm{An}$ inset box gives the personal narrative of Barbara, who concludes her account with a conventionally optimistic message: "Our lives are full, and Jeremy and I have a good strong relationship. And I have really found that time is a great healer" (HFEA, 2005: 51). However, the informational text in the main body of the section, in a concluding discussion of "moving on", makes clear where the responsibility for this positive outcome lies: "it's entirely your decision. There are no right or wrong choices; just the choice that's best for you" (HFEA 2005: 50).

Writing in the context of foetal diagnosis in ante-natal care, Ilpo Helén (2004) argues that the technology is characterised by an ethical split, with technical responsibility attributed to the machinery of reproductive health care, and ethical responsibility, including the making of difficult choices, falling to the women. This ethical split is starkly evident in both the HFEA text and in Winston's, with technical responsibility fulfilled by the provision of "definitive treatment" in the clinical context, but the responsibility for the decision to stop and the production of a positive life without children falling to the women. It is this easily invisible moral and ethical work by women that prompted Rayna Rapp, writing in the context of amniocentesis, to describe women as "moral pioneers" $(1991 ; 1999)$ - a framing that is equally applicable to those for whom IVF fails.

Elspeth Probyn's concept of "outside belonging" (1996) offers a productive means of conceptualising the position in which those for whom IVF fails find themselves. For Probyn, the concept of "outside belonging" articulates "the ways in which belonging is situated as threshold" (1996: 12), and is "always performed with the experience of being within and inbetween sets of social relations" (1996: 13), rather than constituting a stable referent or underlying structure. Identity, therefore, is understood as a process that is "conducted on the surface" in a way which "requires us to constantly place ourselves within relations of proximity of different forms of belonging" (1996: 34). This movement between categories reconfigures the categories themselves, and consequently, this "search for surface connections" (1996: 35 ), she argues, offers significant and novel political possibilities for disrupting the stability of specific identity categories; identity is turned inside out "so that instead of capturing us under its regime of difference as a negative meas- 
ure, the desire of belonging becomes a force that proffers new modes of individuation and of being." (1996: 23).

The inbetweenness of "outside belonging", and its potential to disrupt the polarisation of categories of belonging and identity, is exemplified by the experience of those for whom IVF fails. They find themselves ambiguously located between often contradictory norms of gender, technology and the reproductive body: they have a strong desire to be biological parents, but are no longer actively pursuing that desire, and they have technologised the "natural" reproductive process but without a subsequent baby to counterbalance anxieties about the technological corruption of the natural order. The IVF process itself has also, at various stages of treatment, placed them in an ambiguous category of (non)parenthood in that they have produced embryos, and in most cases, had some transferred to the uterus.

As the analysis of their accounts will demonstrate, the everyday work of negotiating this ambiguous location requires the constant movement between, and reconfiguration of, the reproductive categories of (non)parenthood and (in)fertility, and generates the possibility of new, technologically mediated forms of embodiment that potentially (but never inevitably) protect women from the blame, guilt and exclusion that the experience of the inability to conceive can bring. This, I want to argue, produces precisely the innovation that Thompson only finds in treatment success, and signals the potential for "new modes of individuation and of being" that Probyn describes.

However, it is important to inject a note of caution here, since while IVF fail- ure presents new possibilities for conceptualising the gendered body and the technologies with which bodies interact, it is also an event of protracted and profound grief for those experiencing its effects most directly. As Rosi Braidotti notes: "non-belonging can be hell" (1994: 4). It is important to remember, therefore, that while IVF failure and the end of treatment offers considerable possibility for the rethinking of normative reproductive categories and their relationship to reproductive technology, those possibilities are never mutually exclusive of the personal sadness that each incident of treatment failure represents, and nor is the disruption of those normative categories intended to devalue the aspirations of those seeking treatment to achieve particular forms of belonging. There is, therefore, a distinction to be made between the insights that can be drawn from accounts of IVF failure, and the placing of an expectation on those individuals to embrace the transformative and disruptive possibilities of the situation they have found themselves in. These ideas will be explored in the following two sections, focusing primarily on the accounts of the women themselves.

\section{Fragmenting Childlessness}

The fragmentation which IVF, and its associated technologies, enacts on the unitary categories of reproduction has been widely discussed in the feminist literature on the new reproductive technologies (see, for example, Andrews, 1999; Hartouni, 1997). The use of gamete donation and surrogacy arrangements in conjunction with IVF divides the conventional categories of parent- 
hood across gestational, biological and social lines; cryo-preservation technologies create novel temporal fragmentations, such as the birth of twins years apart; and intra-familial and intergenerational donation and surrogacy arrangements disrupt and reconfigure kinship relations in complex and disorienting ways. However, those same technologies also reconfigure non-parenthood, and treatment failure can be seen to produce a novel form of socially legitimised childlessness; claims to this are dependent on the engagement with IVF. IVF, even when it fails, is mobilised in this context as demonstrative of having tried to have children. The act of trying is constructed as being of moral value in its own right, regardless of the outcome of treatment, effectively legitimising the life without children by making post-IVF non-parenthood fundamentally distinct from that of those who have not undergone treatment.

At the current moment, IVF is the most sophisticated mainstream fertility intervention on the market, and it is this position within the hierarchy of treatments that forms the basis for claims for IVF as definitive. This enables those undergoing treatment to feel assured that every avenue has been explored in the attempt to have children, pre-empting future regrets. But the discourse of having tried IVF also performs an important function in resisting the negative moral judgements of others about their life without children:

Sarah: We'd tried all these things, and even resorted to IVF and it didn't work. So we were convinced we'd done all we could, within reason. So that was good, because if we hadn't, we might have been, you know, we could have done something [...]...Um...in a bit of a horrible sense, it also... for friends who... might be tempted to think "they're a selfish pair, they've chosen not to have kids." This is a bit horrible, but you do get that sense from people. People see you, you have things, you've got money to spend on holidays and things, you've got more free time and they think that you're selfish. And if you say, if they ask "Have you got kids?" and you say "We can't, we had IVF", and they leave you alone.

Claire: [...] I can say "At least I tried". So there can be no stage in the future when I might say to myself, "Oh well, if only I'd tried, it could have been different." Erm...it's almost like I can say to society, "Look, I tried to be the typical female, I tried to be the mother, you know, but it conspired against me, so I now have the right to go off and spend my money on nice holidays or whatever and don't feel guilty."

In both of these extracts, the past engagement with IVF serves not only to reassure Sarah and Claire that they had done all they could, "within reason", at the time, but it also performs a silencing function towards others. The divulgence of the engagement with IVF functions as confessional (Foucault, 1978: 62), which in turn sanctions childlessness post-IVF. In particular, as professional women in double income households, both Sarah and Claire were able to enjoy both the additional free time and disposable income that the life without children can, in some cases, offer. This exposed them to the powerful associations that circulate socially and culturally of certain kinds of consumption with the presumed selfishness of chosen childlessness (see, for example, Morell, 1994; 2000; Tyler May, 1995; 1998; Campbell, 1999). This was a common theme amongst 
those living without children, and several of the women reported deliberately spacing out acts of consumption such as the purchase of a car, soft furnishings or a long trip overseas so as not to draw attention to themselves. The confession of IVF, therefore, becomes a means of earning "the right to go off and spend my money on nice holidays" without the association with "selfish" childlessness. In this case, those who have chosen to live without children, or who have chosen not to engage with IVF, function as the Other against which the participants can establish their own moral status.

Reproductive belonging is rewritten here as defined not by actual reproduction, but by the desire and the intention to reproduce; it is having tried, and significantly, being known to have tried, that produces the socially-legitimised post-IVF body. Indeed, the engagement with IVF enabled several of the participants to construct their own experiences as more demonstrative of the desire to reproduce than "natural" reproduction. Many of the participants' accounts, for example, included narratives of others who had conceived accidentally during casual sexual encounters or through lapses in contraception - stories which not only serve as illustrations of the injustices of infertility, but which also highlight their responsibility, determination and commitment to the reproductive endeavour relative to the apparently easy reproductivity of others.

It is important to note, however, that there is nothing inevitable about the achievement of this socially-legitimised, technologically-mediated childlessness, since it is dependent, firstly, on the willingness to make the engagement with IVF public to some degree, and secondly, on being able to impose a sense of completion onto a technology whose cyclical logic is replete with "maybe-nexttime" promise. There are many reasons for wanting to keep IVF private (see Klock, 1997), and confession always risks social exclusion (for example, from those with strong religious or "pro-life" views on IVF, or from those who perceive IVF as meddling dangerously with the natural order). But in addition to the risks of confession, a more fundamental problem for those undergoing IVF is that while a given amount of treatment may, in retrospect, become constituted as definitive, what actually constitutes the end of treatment is never clear, as Winston himself inadvertently observes:

If you have been through IVF more than once or twice and have had consistent testing then you should know that you have left no reasonable stone left unturned. (Winston, 1999: 222)

This definition of what constitutes leaving no reasonable stone unturned tells those undergoing IVF very little about where the boundary lies between a "reasonable" number of cycles and an excessive and ruinously desperate engagement with IVF. ${ }^{9}$ Furthermore, this highlights the extent to which the very availability of the technology generates new imperatives to engage with it and to engage in the surveillance and disciplining of the self through "consistent testing", but without any objectively identifiable boundaries to those practices. In this study, however, the discursive drawing of those boundaries proved profoundly difficult for some women, and particularly for those who had been forced to stop treatment before they were ready to: for example, as a result of financial 
constraints, the refusal of a partner to participate, or the refusal of clinicians to offer further treatment. The post-IVF body, therefore, and the novel form of socially legitimised childlessness that is associated with it, is not determined by the end of treatment. However, the possibility of being able to lay claim, under certain circumstances, to this technologically-mediated form of socially sanctioned childlessness signals the reconfiguration of the categories of reproductive belonging. This challenges directly the assumption that IVF failure leaves the individual back where they started and the body unchanged.

\section{Reclaiming the Fertile Body}

The second way in which the post-IVF body is produced is through resistance to the identity of "infertile" through the strategic reconfiguration of bodily categories of fertility and infertility.

In biomedical terms, infertility is generally defined as having unprotected sex without conception for a given period of time- usually one to two years. ${ }^{10}$ Particularly in the context of the NHS, this constitutes one of the many eligibility criteria for prospective IVF patients. This direct connection between the definition of infertility and the promise of future treatment positions biomedically-defined infertility as a state of being "not yet pregnant" (Greil, 1991), with the potential for future, technologically-mediated conception and pregnancy still assumed. Infertility here precedes IVF, and is constructed in direct relation to existing medicalised interventions to facilitate conception and pregnancy. In the context of a technology that is conventionally understood as "giving nature a helping hand", and which is also understood as "definitive", the end of unsuccessful treatment can be seen as potentially marking out individual bodies as irretrievably unreproductive. This not only magnifies the body's dysfunction and minimises IVF's own failure to facilitate pregnancy, but synecdochically pathologises the whole woman as "infertile" (Raymond, 1993). In a social and cultural context which places responsibility onto individuals to remain healthy (Lupton, 1995), rather than providing resolution, the end of treatment therefore potentially identifies a problem which the individual continues to bear responsibility to act upon (see also Novas and Rose, 2000). This responsibility, in turn, risks the disruption of the construction of the self as post-IVF.

One of the ways in which the dilemma of the pathologised body was addressed by many of the participants in this study was through the reclamation of the body as fertile, even in the absence of reproduction. This discursive work constitutes the renegotiation of the categories of infertility/fertility in order to avoid the ongoing socio-pathologisation of the body that its labelling as "infertile" produces, repositioning the body outside of the domain of IVF. Perhaps not surprisingly, the participants were very reluctant in the interviews to describe themselves as infertile - a reluctance which reflects the stigma which continues to be attached to the inability to reproduce for both men and women. ${ }^{11}$ One means of managing this potential stigmatisation was to draw a clear distinction between the bodily processes of production and reproduction:

Liz: I think really, the word infertile 
means basically not being able to produce eggs. Erm... I think I do produce eggs... and I still have periods, so I do produce. So I suppose, infertile probably isn't really the right term to use. I suppose it's easier to say "I'm not able to conceive".

Claire:Yeah, I suppose so. Well, yes and no. I mean, I don't know. Because in fact, I mean, my cycle is still, goes on as clockwork. I mean, obviously, I haven't had any hormone measures on my blood done recently, but my periods are still absolutely regular, I still sort of get all the indications of ovulation going on.

Conception and fertility become detached from each other in these accounts, with fertility identified with the production of individual elements of the reproductive process, rather than its end product. This can be understood as a strategic appropriation of dominant representations of the female body in mechanistic terms of production and waste (see Martin, 1989). Within these redefinitions, conception, gestation and birth are no longer treated as the defining criteria for female fertility; instead, eggs, ovulation, hormones and menstruation stand in as equally valid evidence. Claire, for example, described her blocked fallopian tubes as "one tiny, tiny fault in the system that's messed it all up", choosing instead to highlight her normally-functioning hormonal and menstrual systems in support of her claim to fertility. This strategy separates out problematic body parts as unrepresentative of the overall body - a discursive move which resists the synechdochical identification of women with the inability to conceive:

Katy: Well, no [I'm not infertile]. I still have periods, don't I. So I suppose, the only thing that I have got is that inside I'm a mess [laughs]. So there's nothing that... my condition [endometriosis] doesn't allow eggs to stick.

Anne: I think that my fertility was alright. It's just my age was problematic.

In Katy's case, it is menstruation that continues to signal her fertility, with her inability to conceive located within her endometriosis - one of the effects of which is painful periods, making her doubly aware of her ongoing regular menstruation. Anne's location of her infertility in her age is a particularly bold strategy, given the wide-spread criticism of "older" women and reproduction, both within popular culture and within the medical profession (Benley et al., 2005). But what these share is the parcelling off of the problematic body part, or process, as the site of infertility, enabling them to sustain the construction of the body as fundamentally fertile.

This distribution of fertility and infertility around the individual body can be seen as a "parodic repetition" (Butler, 1990) of the medicalised focus on what Rosi Braidotti describes as "organs without bodies" (Braidotti, 1994: ch. 1). But significantly, this knowledge of the body is technologically mediated by the specific experience of fertility treatment, during which hormones, ovarian follicles, the thickness of the uterine wall are all measured, eggs are carefully collected and counted, and embryos are enumerated and graded. These statistics were reproduced faithfully by many of the participants:

Sarah: I think there were 13 follicles and got three eggs, and it didn't work at all.

Angela: Then I was on 6 ampoules, erm, 
produced 22 eggs... no, there were 22 of the little sacs, 21 eggs - and none fertilised.

The recounting of the statistical outcomes of different treatment stages reflects their frustration with the failure of treatment: as Sarah later commented, "it should have worked". But simultaneously, these catalogues of outcomes illustrate their fertility - in this case, in the form of multiple follicles and eggs. For others, the thickness of the lining of the uterus, or the levels of a particular hormone, were recalled with equal specificity. It is also important to note that these specific indicators of fertility are not only technology confirmed via visualisation technologies and medical record-keeping, but are also actively produced by the IVF process. In the case of egg production, for example, it is the regular injections of hormones to stimulate the ovaries that leads to the production of multiple follicles. This is, therefore, a discursive resource for laying claim to the fertile body that is only available to those who have engaged with IVF (or its associated technologies).

The proven knowledge of egg production, even where technologically produced, gave the women in the study access to a discursive reading of the body which is conventionally only available to men in the context of fertility treatment - the idea that "it only takes one" to get pregnant:

June: I didn't consider myself infertile, but I didn't know what was happening as well...It only takes one egg to get fertilised, so I didn't consider myself to be infertile.

Paula: I remember saying to [hospital consultant] when he said about my eggs, "Well, I could still have one, couldn't I?" and he looked at me like I was totally insane. But I said, "Just tell me. There is a possibility that there could be a good one in there." And he said, "Well, there is that possibility." So, even if I never found it, I just need to know that there was a chance.

Paula's insistence that "there could be one good one in there" recalls the assurances that many men are given by partners and doctors when confirmed with a low sperm count that "it only takes one". Indeed, the increased use of technologies such as intro-cytoplasmic sperm injection (ICSI), where a single sperm is injected into an egg to facilitate fertilisation, reinforces this idea:

It [ICSI] can be used (i) for patients with quantitative sperm anomalies, since only a single live (motile) spermatozoon is needed to micro-inject each fertilizable metaphase II oocyte, and (ii) for patients with qualitative semen anomalies [...]". ("Male Fertility Update", 1998, cited in Thompson, 2005: 124; emphasis added)

In contrast, the appropriation by women of the claim that "it only takes one" is highly disruptive of the logic of IVF, which is resistant to the concept of a single egg being sufficient for treatment. Instead, the process of IVF is oriented towards the production of multiple eggs (through the use of hormones), with the "natural" cycle using a single egg considered inefficient and too liable to failure (Thompson, 2005: 260; Winston, 1999: 9). Indeed, the production of very low numbers of eggs is grounds for clinics to refuse further treatment, and several women in this study for whom the hormone regime had only produced a small number of eggs were issued with warnings that a similar outcome in the 
next cycle would lead to the refusal of further treatment. At the clinic through which the participants for this study were recruited, this was signalled in the medical record by the letters "YC" (yellow card) - a football metaphor that implies transgression, and carries an explicit warning about future "performance".

While the claim that there could be "a good one in there" enables women to identify themselves as fertile via a discourse that is normally associated with male bodies, it is also important to note that this is not a direct appropriation. Irma van der Ploeg argues that ICSI constructs sperm as the active agents of reproduction, to which women's eggs and bodies form obstacles, arguing that, "[no] matter how infertile, it seems, a man is never really infertile, provided all 'external conditions' (other bodies, that is) are made conducive to letting his body function" (van der Ploeg, 2004: 167). However, in this study, there were no cases where women constructed the male body as an obstacle to their fertility, even in cases where male factor infertility had been identified (Throsby and Gill, 2004). Instead, the primary obstacles to women's fertility in these accounts were twofold: firstly, their own specific, dissociated, body parts and processes which had been identified as the sites of infertility, as discussed above; and secondly, the technology itself:

Denise: It's not a complete treatment, I think, even though you do get successes. It's still not a complete treatment.

Susan: Medically and statistically, there's absolutely no reason why we shouldn't [get pregnant using IVF]. So there's still that little element of some- thing, I don't know what it is. There's still that element of something, even with all the technological advances, that dictates that only some people have children and some people don't.

By drawing attention to the gaps in medical knowledge about fertility, and to the limitations of the treatment process, the participants were able to sustain the constructions of themselves as fertile. But this also has to be held in tension with the need to construct their own engagement with treatment as sufficient and complete. One means of resolving this tension is by locating IVF within a discourse of scientific progress, whereby they are able to identify themselves as having done everything with the technology that was available at the time, but with the expectation that the current limitations to IVF will be resolved in the future:

Mary: But I can imagine, you know, being about 50 and 60 , feeling quite excited for other people, you know. And they won't have to go through what I went through. And I guess it's the same for people in terms of childbirth, or women that have had particular operations that have suddenly changed over the years or grown more easy.

Katy: I mean, it's... obviously, we knew it was going to improve over the years, presumably it has done. We're sort of a bit out of touch with the extent it has improved. I've heard there are things that they do now...

The moral pioneership of managing the new dilemmas and responsibilities that the technology generates is manifest here in a more literal claim to pioneer status, with Mary identifying herself as pioneering a technology from which others will benefit more consistently in 
the future. Similarly, Katy presumes the ongoing advance of the technology without needing to offer specific details of those presumed developments - a detachment that serves to confirm her post-IVF status. For Rachel, this pioneer status was made even more explicit when she spoke of her decision not to enter into "any further adventure in this kind of field" (my emphasis). She recalled her excitement early in their engagement with IVF, suggesting that they "got caught up with the newness of all the...erm...the new kind of ideas that were coming out to help us". This performs two functions: firstly, it confirms her determination to do everything possible by engaging with every new idea at the time they were pursuing treatment; and secondly, it highlights the newness of the interventions, and therefore, their necessarily imperfect nature.

The acknowledgement of limitations of the technology, and of biomedical understandings of the body, creates a space for the reconfiguration of IVF failure not as the inability of the body to be helped (as in the dominant discourse), but as the inability of IVF, in its current stage of development, to help:

Sharon: It's weird, because I know that I ovulate and everything. It's just because my tube is closed. I know I can get pregnant, because obviously, I've had a baby, and [B's] like fathered a child as well, so it's just the fact that my tube, in between my egg and my uterus... there's something in there blocking the egg getting down. So... I'd call it sub-fertile, yeah. You know, given the help, I'm not infertile, if you see what I mean. You know, I would be able to get pregnant and have a baby.

The category of "sub-fertility" is also used by the HFEA, who suggest that "few couples [...] are infertile; most are 'subfertile' - that is, they have problems that make conception difficult, if not highly unlikely, without medical help" (HFEA, 2005: 11). However, while sub-fertility signifies candidacy for treatment here, Sharon mobilises it, post-IVF, to highlight the inability of IVF to provide the help she would need in order to conceive. This articulates what, to paraphrase the literature on disability (see, for example, Wendell, 1996; Barnes, 1998; Shakespeare, 1998) could be understood as a "social model of infertility", whereby it is external conditions (the limitations of technology) which are understood as accounting for treatment failure, in contrast to the biomedical explanatory model of individually held pathology.

This strategy of highlighting the limitations of the technology itself constructs the body, and particularly the female body, as ultimately unknowable to medical science. This, in turn, leaves an opening for the possibility of future pregnancy:

Courtney: I'd had an ovary removed, and various other things. And it was, "you can't have kids, it's as simple as that". And then I went to see someone else, and he said, "You can't say that because no-one can't have....unless you've got nothing there... but no-one can't have kids". It's just I can't do it naturally. I've got all the bits there.

The argument that you can never say never - that "no-one can't have kids" as long as all the "bits" are there - has significant social currency. Indeed, the participants recalled with some irritation being regaled throughout their treatment, and beyond it, by doctors, family members, colleagues and friends with 
stories of unexpected, long-awaited pregnancies - stories which were wellintended as sources of encouragement, but which often harbour implicitly woman-blaming messages about the importance of needing to relax, being more sexually adventurous, or eating differently. But in spite of their annoyance with others over these stories, they were able to mobilise them to useful effect in their accounts:

Tim: There is a chance, because you read in the papers that it happens. Katy: People get miracles. Tim: It might just happen. You never know.

Anne: Sometimes... I wonder if I will [get pregnant]. And erm... because people just do. People who've been through fertility treatment, you know.... Very occasionally they do.

These claims to the unpredictability of the female body echo the familiar construction of women's bodies as uncontainable and beyond control (see Shildrick, 1997: 27), with reproduction signifying the contradictory states of both "natural" order and disorder. But significantly, even though Tim and Katy, and Anne, insist that "people get miracles", this does not necessarily reflect the active pursuit of pregnancy. Most of the women in this study, including Katy and Anne, had already abandoned the meticulous monitoring of the body for signs of fertility and pregnancy that conventionally accompanies the experience of infertility, such as charting basal body temperature, assessing cervical mucus, or using ovulation prediction kits. ${ }^{12}$ Similarly, most had ceased to take supplements such as folic acid in preparation for pregnancy, and had disengaged from a wide range of alternative health prac- tices oriented towards facilitating conception and a healthy pregnancy. Instead, I would argue that these claims that "people just do" are part of the transitional discursive work out of the "not yet pregnant" body to the post-IVF body through the dissociation of the self from the label of "infertile".

It is important, however, not to overstate this transfer of responsibility for treatment failure onto the technology itself. Indeed, one of the key findings of this research is the extent to which the successes of IVF become attributed to the technology but that women tend to be constructed both by themselves and others as culpable for its failures (Throsby, 2004: ch. 6; Throsby and Gill, 2004). ${ }^{13}$ One of the most common features of the interviews was the expression of feelings of guilt and responsibility: for having "let down" partners, family members and doctors; for being "rubbish at producing eggs" (Jenny); for things that they had consumed, or not consumed, that may have contributed to a negative outcome; for not being sufficiently relaxed; or for past "transgressions" such as terminations earlier in life. This apparent contradiction between the highlighting of the limitations of IVF and the expression of feelings of personal guilt and responsibility illustrate the competing and contradictory discourses of gender, technology and the body that those accounting for the experience of IVF failure have to negotiate. In the case of the highlighting of the limits of IVF, and of biomedicine, to know the female body, I would argue that this should be seen in terms of a discursive strategy to facilitate the construction of the body as always potentially capable of conception and pregnancy, rather 
than constituting a wholesale transfer of responsibility onto the technology. This is not least because although this focus on the limits of the technology does shift the focus of attention to some extent away from the women, IVF and its practitioners are never treated as morally culpable for failure in these accounts in the way that the women are when responsibility is attributed to them. Returning to Ilpo Helén's argument, in these accounts, IVF and its practitioners have fulfilled their technical responsibilities within the technologies available to them, while ethical responsibility remains with the women.

\section{Conclusion}

When IVF fails it leaves a small number of literal marks on the body, especially in the short term. Participants in this study reported scarring on their thighs after repeated injections; others had small laparoscopy scars on their abdomen from earlier fertility investigations; several reported weight gain which they attributed to a combination of the drugs they had taken during treatment, and to comfort eating in order to manage the stress of treatment. But these are small, relatively transient, marks, and in the absence of the very obvious physical transformations of the pregnant body, Thompson's (2005: 9) claim that ontological innovation only occurs when treatment succeeds is, at first glance, easily plausible. However, as the analysis presented here has demonstrated, the unsuccessful engagement with IVF generates the possibility of new ways of being, via novel, IVF-mediated categories of childlessness and fertility. These innovations destabilise the convention- ally fixed categories of reproductive belonging, not through their rejection, but through their reconfiguration - a process which undermines the exclusions which those rigid categorisations of difference produce. This discursive work of constructing the post-IVF body, I have argued, can be understood through the lens of "outside belonging", which Probyn mobilises "against certain categorical tendencies and the rush to place differences as absolute" (1996: 9).

This work of reconfiguration and destabilisation is quietly disruptive in a way that lacks the spectacle of the more photogenic and headline-grabbing products of the new reproductive and genetic technologies. Indeed, it could be argued that a focus within feminist technoscience on the very urgent demands of the more spectacular novelties of the new reproductive and genetic technologies risks reproducing the focus on treatment success that renders experiences of failure invisible. ${ }^{14}$ Just as Probyn is drawn to the "ordinariness" and "fundamental shabbiness" (1996: 4) of Montreal as her starting point for articulating "outside belonging", it is the everyday-ness of managing IVF failure that is at the heart of its destabilising potential, through its ongoing and necessarily sustained challenge to the taken-for-granted categories of reproduction - a challenge that is oriented not towards disruption and transgression, but to belonging. It is important not to overstate the transgressive nature of this discursive work, since it is ethically problematic to transfer the expectations of feminist politics onto individuals who do not necessarily take pleasure in the disruption of the very categories to which they strive to belong, and for whom a 
great deal is at stake in the success of that endeavour. The construction of the postIVF body, and its subsequent categorical destabilisation, only makes sense in a social and cultural context within which the norms of reproduction and of the gendered body are so closely intertwined. The post-IVF body, therefore, requires constant reiteration, and is only made meaningful through the confession of IVF - a process which (potentially) exposes individuals to the negative evaluation of others. The frontiers which the moral pioneers of IVF inhabit, therefore, are locations not only of intense possibility, but also of risk - risks which are borne by those undergoing treatment.

Furthermore, there is nothing inevitable about the post-IVF body, and for some, the transition out of being "not yet pregnant" is simply unattainable. Within Winston's formulation, the responsibility for this falls directly onto the women themselves for "[allowing] their treatment to destroy their well-being and to destroy the things and relationships they most value" (1999: 223), but this is to ignore the extent to which the material and discursive resources to make that transition do not lie within the remit of the individual. As this research has shown, the imposition of an unwelcome end to treatment through lack of funds, the refusal of doctors to provide further treatment, or the refusal of a partner to participate in further cycles all proved to be disruptive of attempts to construct the self as having done everything possible to have children. Similarly, several of the women found themselves trapped, post-IVF, in jobs that they did not enjoy, but which they had stayed in longer than they had originally intended in order to access enhanced maternity benefits if they got pregnant; others had bought houses with future children in mind, with rooms picked out for nurseries, and good access to local schools, serving as constant reminders of their unchosen childlessness.

It is also important to note that just as there is nothing inevitable about the post-IVF body, its achievement is never fixed, and does not form part of a linear progression or "moving on". Indeed, many of the participants moved back and forth between being "not yet pregnant" and being able to position themselves as post-IVF. Several reported being prompted to return to treatment by particular events such as the pregnancy of a friend or family member, or a news story of a new type of treatment. For others, the unanticipated and delayed offer of a health authority funded cycle, or an unexpected influx of personal funds (for example, from an inheritance, a work bonus, or in one case, a small lottery win) prompted a return to treatment. Unsuccessful IVF, then, rarely offers the absolute resolution that is claimed for it, and nor is it an absence of change that takes women precisely back to where they started. Rather, it constitutes an ongoing task of negotiation between the limited discursive resources available to them for accounting for those experiences.

In making this argument, and in focusing on the high likelihood of treatment failure, I am categorically not attempting to proscribe the strong desires of individual women to have children, and nor am I suggesting either that women should not engage with technologies such as IVF. What I am arguing, however, is that presumptions either 
that the meanings of the unreproductive body are unchanged post-IVF, or that the conclusion of treatment is necessarily experienced positively (or catastrophically), cannot be taken for granted. These presumptions, I suggest, reproduce the idea that it is only treatment success that produces significant change and innovation and therefore reiterate representations of success as definitional of the technology. This overlooks the work of the everyday (re)production of a post-IVF body that is as novel and innovative as IVF's miracle babies.

\section{Acknowledgements}

This research was supported by a doctoral studentship from University of London Triangle Trust, the Metcalfe Studentship for Women (London School of Economics) and an Economic and Social Research Council Postdoctoral Fellowship, for which I am very grateful. I would also like to thank the editors and the anonymous reviewers for their constructive and encouraging comments.

\section{Notes}

1 A notable exception to this would be Margaret Sandelowski's book With Child in Mind: Studies of the Personal Encounter with Infertility (1993), which includes a discussion of people's experiences of successful IVF and how the experience of infertility and the use of the technology impacts upon the experience of pregnancy. She also addresses issues of IVF failure, and of adoption.

2 Statistics published for the UK in 2005 for the period April 2002 - March 2003 show success rates of $27.6 \%$ for women under $35,22.3 \%$ for women aged $35-37,18.3 \%$ for women aged $38-39$, and $10 \%$ for women aged 40-42 (www.hfea.gov.uk/
PressOffice/Factsandfigures).

3 It is also the case that even when IVF succeeds, in most cases, the original condition responsible for the difficulties in conceiving is rarely changed, but rather, successfully circumvented.

4 This is used in the sense that Jane Ussher articulates as a means of "attempting to reconcile a critical analysis with a recognition of the materiality of people's lives" (1997: 7).

5 Initially, there were 36 positive and 32 negative responses, with 45 letters returned to sender. Eight of those who had responded positively subsequently withdrew. People were not asked to give reasons for non-participation, but some offered explanations spontaneously. These included: still undergoing treatment, not wanting to revisit that difficult experience or undergoing personal difficulties at the time of the request.

6 All IVF patients are offered independent counselling throughout the treatment process, including when treatment fails, although very few of the participants had made use of this at the time of their treatment.

7 The term "giving up" can be seen as problematic in itself, since it applies a lack of commitment and persistence. Ann Woollett, for example, identified this as a feature of infertility and self-help literature (Woollett, 1996: 75).

8 This is a theme that is developed elsewhere in the publication. For example, a section entitled "When it doesn't happen..." is illustrated with a full page montage of clock-faces (HFEA, 2005: 10-11).

9 For a further discussion of the problems of establishing how much IVF is neither too little nor too much, see Throsby (2002; 2004).

10 The HFEA Guide to Infertility and Directory of Clinics (2005) recommends a period of 18 months to 2 years of trying to conceive; the National Institute for Health and Clinical Excellence (NICE) recommends a two year period before seeking 
treatment (NICE, 2004).

11 Although it is important to note that this process of stigmatisation works very differently for men and women (Meerabeau, 1991; Throsby and Gill, 2004; Webb and Daniluk, 1999).

12 These practices were not part of the IVF process itself, but were part of the women's daily lives before engaging with IVF and in between cycles. Several of the women I interviewed still considered themselves to be "trying for a baby" and had continued these monitoring practices after stopping IVF.

13 This attribution of responsibility is not confined to IVF, and can be seen in the more general trend to hold women responsible for reproductive outcomes, and to construct the female body as inherently unpredictable and liable to failure (see, for example, Ladd-Taylor and Umansky, 1998; Oudshoorn, 1994; Shildrick, 1997)

14 This is not to suggest that feminists should not continue to work on these more spectacular entities. Indeed, there is a strong case to be made for feminists engaging proactively with the cutting edge of the new reproductive and genetic technologies, rather than reactively. Instead, I am arguing that this research needs to be placed in the broader context of women's lived experiences of those technologies, particularly given the centrality of IVF to them, both as a specific procedure (the fertilisation of eggs in the laboratory) and as a fertility treatment, since IVF remains the primary source of embryos for research.

\section{References}

Andrews, L. B.

1999 The Clone Age: Adventures in the New World of Reproductive Technology. New York: Henry Holt and Company.

Barnes, C.

1998 Exploring Disability: A Sociological Introduction. Oxford: Polity.
Benley, S., Davies, M. \& Braude, P.

2005 "Which career first?" British Medical Journal 331: 588-589.

Braidotti, R.

1994 Nomadic Subjects: Embodiment and Sexual Difference in Contemporary Feminist Theory. New York: Columbia University Press.

Brian, K.

1998 In Pursuit of Parenthood. Real-life Experiences of IVF. London: Bloomsbury.

Butler, J.

1990 Gender Trouble: Feminism and the Subversion of Identity. London: Routledge.

Campbell, A.

1999 Childfree and Sterilized: Women's Decisions and Medical Responses. London: Cassell.

Daniluk, J. C.

1996 "When treatment fails: the transition to biological childlessness for infertile women." Women In Therapy 19(2): 8198.

Foucault, M.

1978 The History of Sexuality. An Introduction. London: Penguin Books.

Franklin, S.

1993 "Making representations: the parliamentary debate on the Human Fertilisation and Embryology Act." Pp. 127170 in Edwards et al. (eds.), Technologies of Procreation: Kinship in the Age of Assisted Conception. London: Routledge.

1997 Embodied Progress: A Cultural Account of Assisted Conception. London: Routledge.

Gill, R.

1996 "Discourse analysis: practical implementation." Pp. 141-158 in Richardson (ed.), Handbook of Qualitative Research Methods for Psychology and the Social Sciences. Leicester: BPS Books.

2000 "Discourse analysis." Pp.172-190 in Bauer and Gaskell (eds.), Qualitative Researching with Text, Image and Sound: A Practical Handbook. London: Sage.

Greil, A. L.

1991 Not Yet Pregnant: Infertile Couples in Contemporary America. New Brunswick: Rutgers University Press. 
Hartouni, V.

1997 Cultural Conceptions. On Reproductive Technologies and the Remaking of Life. London: University of Minnesota Press.

Helén, I.

2004 "Technics over life: risk, ethics and the existential condition in high-tech antenatal care." Economy \& Society 33(1): 28-51.

Human Fertilisation and Embryology

Authority (HFEA)

2005 HFEA Guide to Infertility and Directory of Clinics. London.

Klock, S. R.

1997 "To tell or not to tell: the issue of privacy and disclosure in infertility treatment." Pp.167-188 in Leiblum (ed.), Infertility: Psychological Issues and Counselling Strategies. New York: John Wiley and Sons.

Ladd-Taylor, M. \& L. Umansky (eds.)

1998 "Bad" Mothers: The Politics of Blame in Twentieth Century America. New York: New York University Press.

Lupton, D.

1995 The Imperative of Health: Public Health and the Regulated Body London: Sage.

Martin, E.

1989 The Woman In The Body. A Cultural Analysis of Reproduction. Milton Keynes: Open University Press.

McGrail, A.

1999 Infertility: The Last Secret. What Happens When You Want To Have A Baby. London: Bloomsbury.

Meerabeau, L.

1991 "Husbands' participation in fertility treatment: they also serve who only stand and wait." Sociology of Health

Morell, C. and Illness 13(3): 396-410.

2000 "Saying no: women's experiences with reproductive refusal." Feminism and Psychology 10(3): 313-322.

1994 Unwomanly Conduct: The Challenges of Intentional Childlessness. London: Routledge.
National Institute for Health and Clinical Excellence (NICE)

2004 Assessment and Treatment for People with Fertility Problems. Understanding NICE Guidance - Information for People with Fertility Problems, Their Partners and the Public. London: NICE.

Novas, C. \& Rose, N.

2000 "Genetic Risk and the Birth of the Somatic Individual." Economy and Society 29(4): 484-513.

Oudshoorn, N.

1994 Beyond the Natural Body: An Archaeology of Sex Hormones. London: Routledge.

Parry, S.

2003 "The politics of cloning: mapping the rhetorical convergence of embryos and stem cells in parliamentary debates." New Genetics and Society 22(2): 45168.

Potter, J. \& Wetherell, M.

1987 Discourse and Social Psychology: Beyond Attitudes and Behaviour. London: Sage.

Probyn, E.

1996 Outside Belongings. London: Routledge.

Rapp, R.

1991 "Moral pioneers: women, men and fetuses on a frontier of reproductive technology." Pp. 383-395 in de Leonardo (ed.), Gender at the Crossroads of Knowledge: Feminist Anthropology in the Postmodern Era. Berkeley: University of California Press.

1999 Testing Women, Testing the Fetus: the Social Impact of Amniocentesis in America. London: Routledge.

Raymond, J. G.

1993 Women as Wombs. Reproductive Technologies and the Battle over Women's Freedom. San Francisco: Harper San Francisco.

Sandelowski, $\mathrm{M}$.

1993 With Child In Mind. Studies of the Personal Encounter with Infertility. Philadelphia: University of Pennsylvania Press.

Sawicki, J.

1991 Disciplining Foucault: Feminism, Power and the Body. London: Routledge. 
Shakespeare, T.

1998 The Disability Reader: Social Science Perspectives. London: Cassell.

Shildrick, M.

1997 Leaky Bodies and Boundaries: Feminism, Postmodernism and (Bio) Ethics. London: Routledge.

Thompson, C.

2005 Making Parents: the Ontological Choreography of Reproductive TechnoloThrosby, K. gies Cambridge, Mass.: MIT Press.

2002 "Negotiating 'Normality' When IVF Fails." Narrative Inquiry 12(1): 43-65.

2004 When IVF Fails: Feminism, Infertility and the Negotiation of Normality Basingstoke: Palgrave.

Throsby, K. \& Gill, R.

2004 "It's Different for Men: Masculinity and IVF." Men and Masculinities 6(4): 330348.

Tyler May, E.

1995 Barren in the Promised Land: Childless Americans and the Pursuit of Happiness. Cambridge: Harvard University Press.

1998 "Nonmothers as bad mothers: infertility and the 'maternal instinct'." Pp. 198219 in Ladd-Taylor and Umansky (eds.), "Bad" Mothers: The Politics of Blame in Twentieth-Century America.

Ussher, J. New York: New York University Press.

1997 "Introduction: towards a material-discursive analysis of madness, sexuality and reproduction." Pp. 1-9 in Ussher (ed.), Body Talk: the Material and Discursive Regulation of Sexuality, Madness and Reproduction. London: Routledge.

van der Ploeg, I.

2004 “'Only angels can do without skin': on reproductive technology's hybrids and the politics of body boundaries." Body \& Society 24(2-3): 153-181.

Webb, R. \&. Daniluk, J. C.

1999 "The end of the line: infertile men's experiences of being unable to produce a child." Men and Masculinities 2(1): 625.
Wendell, S.

1996 The Rejected Body: Feminist Philosophical Reflections on Disability. London: Routledge.

Winston, R.

1999 The IVF Revolution: The Definitive Guide to Assisted Reproductive Techniques. London: Vermilion.

Wood, L. A. \& Kroger, R. O.

2000 Doing Discourse Analysis: Methods for Studying Action in Talk and Texts. Lon-

Woollett, A. don: Sage.

1992 "Psychological aspects of infertility and infertility investigations." Pp. 152-174 in Nicolson and Ussher (eds.), The Psychology of Women's Health and Health Care. London: Macmillan Press.

1996 "Infertility: from 'inside/out' to 'outside/in'." Feminism and Pyschology 6(1): 74-78.

Karen Throsby

Department of Sociology

University of Warwick, UK

k.throsby@warwick.ac.uk 